\title{
Systematic assessment of damage to buildings due to groundwater lowering-induced subsidence: methodology for large scale application in the Netherlands
}

\author{
Ana Laura $\operatorname{Costa}^{1}$, Sien Kok ${ }^{1}$, and Mandy Korff ${ }^{1,2}$ \\ ${ }^{1}$ Deltares, Delft, $2600 \mathrm{MH}$, the Netherlands \\ ${ }^{2}$ Department of Geoscience \& Engineering, TU Delft, Delft, 2628 CN, the Netherlands \\ Correspondence: Ana Laura Costa (analaura.costa@deltares.nl)
}

Published: 22 April 2020

\begin{abstract}
In the Netherlands, subsidence of peat and clay soils due to (artificial) lowering of the groundwater table and loading of soft soils is commonplace, causing extensive damage to exposed and vulnerable assets. Awareness of subsidence-related damage to buildings has recently increased in the Netherlands, particularly after reported damages due to the 2018 extremely long dry period. However, despite this being a major concern to homeowners and public authorities, an integrated and systematic risk assessment on regional or national scale is currently lacking which inhibits concrete and meaningful action. In this paper, we propose a methodology for the systematic regional or countrywide assessment of two subsidence-related damage mechanisms to buildings: differential settlement of buildings on shallow foundation, and timber pile degradation due to low groundwater levels. The methodology is set up in a modular, systematic way - initially based on expert judgement and validation with available local detailed information and allows for future improvements. Progress in individual contributing factors to damages can be seamlessly integrated for the systematic improvement of damage estimates. This approach can be replicated for other damage mechanisms and detailed to provide a more local risk assessment. We expect results to be a valuable input for public or private decision making, e.g. in awareness raising and evaluating interventions.
\end{abstract}

\section{Introduction}

In the Netherlands, subsidence of peat and clay soils due to (artificial) lowering of the groundwater table and loading of soft soils is commonplace, causing extensive damage to exposed and vulnerable assets. Improved risk assessment of subsidence-related damage to buildings would inform public and private actors from national to local scale on current and future risks and stimulate them to address this issue. Earlier efforts to assess subsidence-related building damage in the Netherlands at the national level predict significant direct damage - ranging from at EUR 17-45 billion cumulative by 2050 (van den Born et al., 2016; Hoogvliet et al., 2012) - but fail to address probability and impact of climate change, and do not provide a systematic and scalable approach to do so. Several factors complicate a large scale, realistic risk assessment. On the hazard side, multiple drivers of subsidence act- ing at various spatial scales lead to a high spatial variability of hazard conditions: e.g., local influences on the groundwater table (trees, leaking pipes) and variability in susceptibility of soft soils to settle (e.g. presence of anthropogenic layer). On the side of the assets at risk, challenges exist in systematically assessing the exposure and vulnerability of buildings to subsidence. Aside from a knowledge gap regarding the vulnerability functions (linking building damage to subsidence), databases with key input such as foundation types and historic design practices are incomplete or non-existent.

Authors in other countries have used contingent valuation and expert judgement to estimate a relationship between subsidence and building value loss (Lixin et al., 2010; Warren and Jones, 1975) but such an approach is not directly scalable to the national level, and the Dutch housing market, e.g. due to the large variety of building and foundation practices in the Netherlands. 
In this paper, we propose a methodology for systematic regional or countrywide assessment of two subsidence-related damage mechanisms to buildings: timber pile degradation due to low groundwater levels and differential settlement of buildings on shallow foundations.

\section{Methodology}

The risk assessment carried out for the estimation of damage to buildings due to groundwater lowering-induced subsidence is construed in a modular, systematic way that allows for continuous improvement. Two damage mechanisms are studied and for each mechanism 3 modules are built based upon the conceptual framework of Hazard - Exposure - Vulnerability according to the definitions by the UNISDR (2016), with:

i. Hazard - characterizing the events causing damage; in this case subsidence and/or low groundwater levels;

ii. Exposure - inventory of the building assets at risk (on shallow foundations exposed to differential settlements or on timber piles exposed to pile degradation); and

iii. Vulnerability - Defining the degree of physical damage (architectural, functional and/or structural) of the buildings at risk.

This approach is particularly suited for large scale applications for two main reasons.

Firstly, by establishing correlations between the varying hazard levels, the characteristics and value of the buildings at risk and the expected degree of damages, for a spectrum of conditions, the methodology is applicable to large areas; it can be spatially extended limited only by availability of data or time/resources and the level of detail can be adjusted to the context and purpose of the analysis.

Secondly, the incremental availability of better-quality information for each of the modules, often studied individually by different expert groups, can be incorporated seamlessly, thus providing flexibility in improving the results.

\section{Data and function collection}

Different types of information are used for the damage assessment, characterizing each of the hazard, exposure and vulnerability modules:

- Mapped data defining the spatial properties of the hazard and the areas threatened and non-threatened (i.e. low groundwater levels and subsidence);

- Mapped data identifying the location of the buildings and their characteristics such as the building period, and type and depth of foundation, key structural aspects etc.

- Tabulated data defining the probability of different building characteristics within specific areas;
- Vulnerability functions or tables defining the degree of damage for specific conditions (e.g. the degree of damage resulting from an $x$ amount of building settlement in a building of typology $y$ );

- Expected damage restoration costs linked to varying degrees of damage.

Created maps are numbered for easiness of reference. The data is analyzed in GIS and separate correlations can be established to differentiate the effect of different characteristics such as types of foundations, etc. The level of detail with which these components are explored in a damage assessment, however, is dependent on the context and purpose of the analysis.

Two expert sessions were organized to complement and check the data and function collection based on local experience: one for the hazard module and another for the exposure and vulnerability of the buildings.

The holistic approach in the expert sessions contributed to the management of expectations and the communication of trade-offs between the accuracy of the results and the quality of the input that needs to be available.

\section{Damage Assessment - Application to the Netherlands}

Figures 1 and 2 illustrate the methodology for the calculation of damages due to, respectively, timber pile degradation caused by fungi as induced by low groundwater levels and differential settlement of buildings on shallow foundations. The data is herein discussed per module: hazard $(\mathrm{H})$, exposure (E) and vulnerability (V).

\subsection{Hazard}

\subsubsection{Timber Pile Degradation}

Different causes can lead to decay of timber pile foundations (Klaassen, 2015) one of the main ones being the decline of the ground water table, a reality in areas of continuous subsidence in the Netherlands to prevent flooding.

H1 - The key indicator characterizing the triggering of the mechanism is the low ground water level (GLG in Dutch) and maps are readily available for the Netherlands. Source: https://www.wur.nl/ (last access: 26 February 2020).

\subsubsection{Differential settlement of buildings on shallow foundation}

In general, a differential settlement of a building can be directly linked to heterogeneous conditions of the soil, heterogeneous conditions of the building itself or a combination of both. In this application we assume that the (shallow) subsidence rate of the soil (H9), when corrected for factors of local 


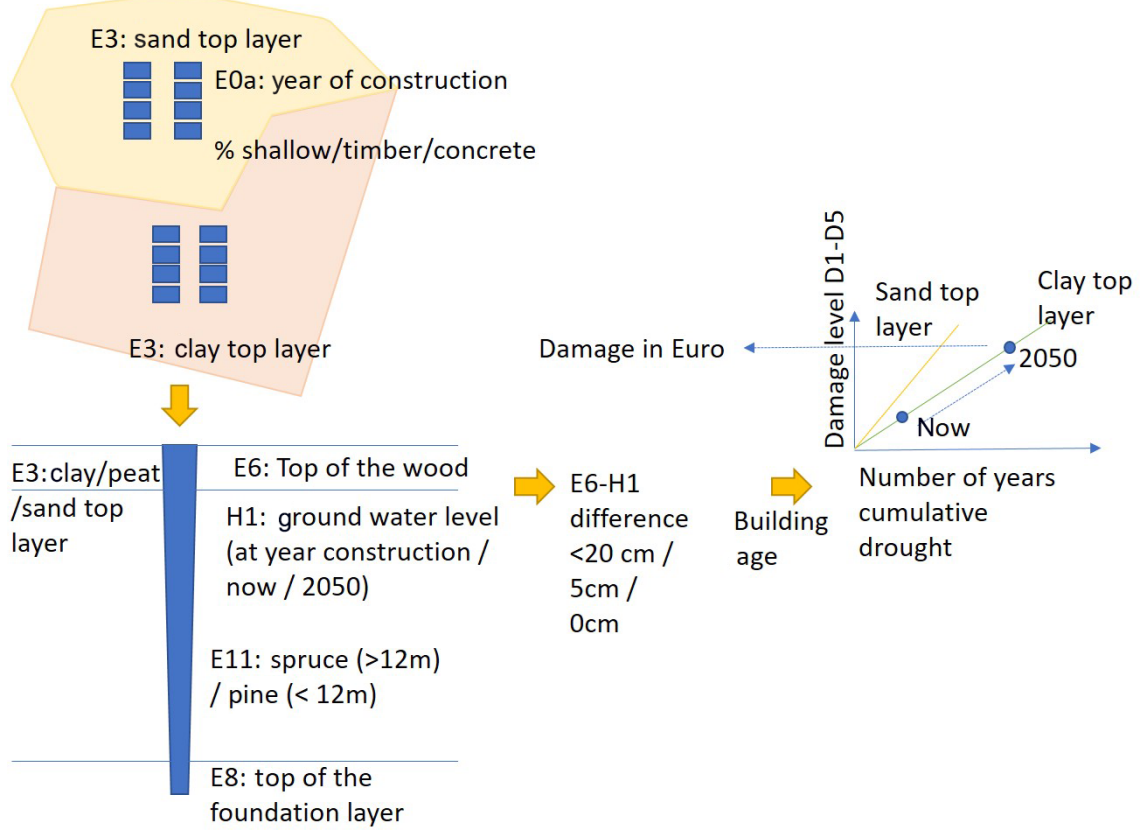

Figure 1. Schematic for the calculation of damages due to timber pile degradation induced by low groundwater levels.

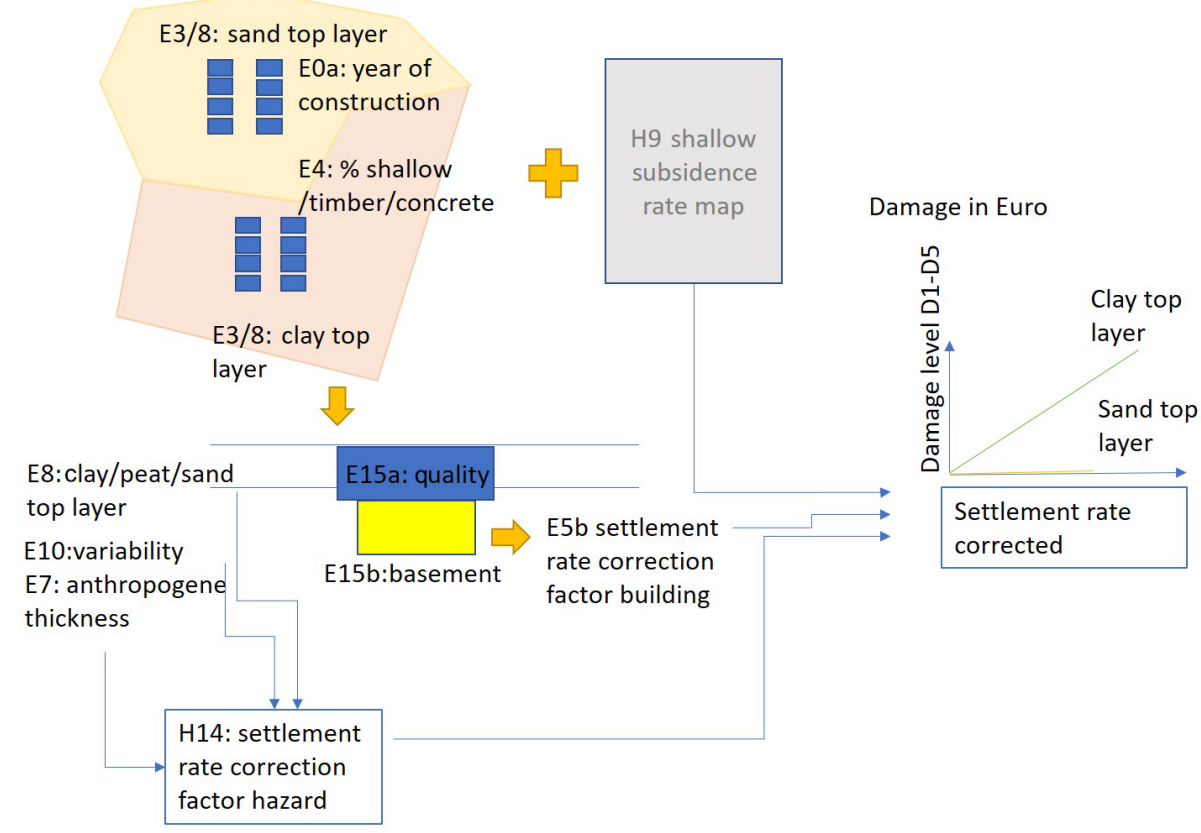

Figure 2. Schematic for the calculation of damages due to differential settlement of buildings on shallow foundations.

hazard (H14) and for building characteristics (E5b), correlates to the damage of the building. The data is herein discussed per module.

H9 - Defines the shallow subsidence rate, thus excluding subsidence triggered by gas extraction, at a national level. Source: https://bodemdalingskaart.nl/ (last access: 26 February 2020).
E7 - Defines the anthropogenic layer thickness, based on information from Geotop (https://www.dinoloket.nl, last access: 26 February 2020) and extrapolations for different urban and rural areas from available in situ data at the Dutch knowledge center of foundations (KCAF). 
E8 - Defines the type of soil at $1-2 \mathrm{~m}$ depth, as presented in Sect. 3.1. In the context here, the type of soil near the surface represents potential for swell/shrinkage behavior of clay.

E10 - Represents the local variability in the susceptibility to settlement as an indicator of the heterogeneity in subsurface. This is represented by the standard deviation of readily available maps of susceptibility to settlement. Source: https://bodemdalingskaart.nl/.

H14 - Defines the correction factor (CF) for the settlement rate for local hazard by aggregating partial correction factors for each of E7, E8 and E10. As a proxy for how aggravating the combined local hazard conditions are in relation to the nationwide subsidence rate estimates, $\mathrm{CF}>1$ for increased differential settlement potential at the building level and $\mathrm{CF} \leqq 1$ if otherwise.

\subsection{Exposure}

The exposure characterizes the buildings that are at risk. Key indicators for the exposure are the foundation types, characteristics and location. The foundations can be classified into three major types: shallow foundations, timber piles, and other (mainly concrete) piles.

The same indicators are used for the second damage mechanism. The list below discusses the exposure indicators of the analysis per foundation type.

E0a-Map combining location of all the buildings in the Netherlands (database source: the Basic Registration of Addresses and Buildings (BAG) - http://www.kadaster. nl/bag, last access: 26 February 2020 - that contains the official data of all addresses and buildings in the Netherlands).

E3 - Map identifying the areas of clay and peat where timber pile foundations and shallow foundations are expected. Ideally this map would reflect the type of soil in the top 12-15 m. This application to the Netherlands is based on the second layer of Geotop (https://www. dinoloket.nl), representing $1-2 \mathrm{~m}$ depth, that have nationwide coverage.

E4 - Defines regional areas of typically similar foundations based on historical practice. This map defines foundation type probability per building, per area (E4) and per soil type (E3) based on the expert sessions and local inventories in limited locations. Ideally an inventory of foundation type for all buildings would exist at the local level, but this is not currently the case.

E4b - Classifies the land-use type into rural or urban areas.

Exposure indicators specific to each damage mechanism are also defined, in addition to the common indicators described above.
Table 1. Exposure classes for timber piles.

\begin{tabular}{lll}
\hline $\begin{array}{l}\text { Exposure } \\
\text { class }\end{array}$ & Boundary values & $\begin{array}{l}\text { Number of dry } \\
\text { days per year }\end{array}$ \\
\hline Low & GLG - top of wood: $>20 \mathrm{~cm}$ & Low \\
Medium & GLG - to of wood: $5-20 \mathrm{~cm}$ & Medium \\
High & GLG - top of wood: $<5 \mathrm{~cm}$ & High \\
\hline
\end{tabular}

\subsubsection{Timber Pile Degradation}

E6 - Defines the level of the top of the timber piles per area of E4, based on an inventory data available at the Dutch knowledge center of foundations (KCAF).

E8 - Defines the type of soil at the top of the timber piles. Piles in more permeable soils can be more severely affected by droughts as moisture content drops faster. It is assumed that the second layer of Geotop (https://www.dinoloket.nl), representing 1-2 m depth, is representative.

E11 - Defines the estimated type of timber of the piles, with a binary classification into spruce and pine, representing the large majority of timber used (Schreurs, 2017). A threshold of $12 \mathrm{~m}$ length defines the timber type: spruce was typically available and used for piles longer than $12 \mathrm{~m}$ and pine if shorter.

E12 - Classifies the type of timber pile foundation into Amsterdam style (two timber piles under a foundation beam) or Rotterdam style (single timber pile foundation). Based on the expert sessions the application considers that, nationwide, $80 \%$ of foundations are the Rotterdam type and $20 \%$ are the Amsterdam type; the exceptions are in Amsterdam where $100 \%$ is the Amsterdam type and all buildings with more than 4 floors are also with Amsterdam type. The different types of piles can relate to different failure modes and thus have distinct vulnerabilities.

Exposure classes for timber piles are then established based on E1 and E6 (Table 1), with boundary values derived from guidelines from the Dutch organization for independent foundation research $(\mathrm{F} 3 \mathrm{O}, 2014)$.

\subsubsection{Differential settlement of buildings on shallow foundation}

E15a - Classifies the expected structural quality of the shallow foundation into low, medium and high based on the year of construction.

E15b - Defines the presence or absence of a uniform or partial basement under the building. 
Table 2. Settlement correction factors for building features.

\begin{tabular}{lll}
\hline Map & Factor & Partial coefficient \\
\hline E15a & Quality of masonry & High: $80 \%$ \\
& & Medium: $100 \%$ \\
& & Low: $120 \%$ \\
\hline \multirow{2}{*}{ E15b } & Presence of full basement & Yes: $80 \%$ \\
& & No: $100 \%$ \\
\cline { 2 - 3 } & Presence of partial basement & Yes: $120 \%$ \\
& & No: $100 \%$ \\
\hline
\end{tabular}

E5b - Defines the settlement rate correction factor for the building characteristics by aggregating partial correction factors (Table 2) for each of E15a and E15b.

\subsection{Vulnerability}

\subsubsection{Timber Pile Degradation}

The degree of damage to the buildings is related to the pile degradation. Key factors for the pile degradation by fungi include: the type of the wood and the diameter of the pile (commonly associated), the type of soil and its moisture content and the duration of the drought. Note also that the type of timber pile foundation - Amsterdam style (two timber piles under a foundation beam) or Rotterdam style (single timber pile foundation) - can relate to different failure modes and this detailed analysis shall be taken into account in further developments.

In this application, the duration of the drought is the factor considered to define building damage the general assumption is that after a cumulative drought of 10-20 years, i.e. the cumulative number of dry days over a longer time span, spruce timber piles with a diameter 20-25 are degraded fully (KCAF, 2012). For pine this period is generally much shorter and currently taken as 1-2 years. A linear trend of the damage level with time is assumed as a first approximation, ranging from damage level D1 to D5 eventually (Burland and Wroth, 1974).

\subsubsection{Differential settlement of buildings on shallow foundation}

Traditional vulnerability curves are commonly based on differential settlement over time. However currently no probability of such a differential settlement is available. Therefore, damage classes are assigned to each of the buildings based on the rate of settlement with correction for factors of local hazard (H14) and for building characteristics (E5b) as presented in Fig. 2. The damage classes are detailed in the next section.
Table 3. Damage classes and restoration costs.

\begin{tabular}{ll}
\hline $\begin{array}{l}\text { Damage } \\
\text { class }\end{array}$ & $\begin{array}{l}\text { Restoration costs per } \\
\text { cubicmeter of building }\end{array}$ \\
\hline 1 & EUR 3.25 \\
2 & EUR 15 \\
3 & EUR 53 \\
4 & EUR 184 \\
5 & EUR 670 \\
\hline
\end{tabular}

\subsection{Expected damage assessment}

To arrive at a national level estimate of expected damage, all information and indicators are collected at the building level, to define the expected damage level in 2050. For both damage mechanisms, this level is expressed in classes ranging from 1-5, applicable to both damage mechanisms, with D1 representing negligible damage, i.e. hairline cracks of $<0.1 \mathrm{~mm}$, and D5 severe structural damage involving partial or complete rebuilding of the structure (Burland and Wroth, 1974). Based on desk research and interviews with experts active in building restoration sector in the Netherlands, Salerno (2017) estimates restoration costs for Dutch buildings (Table 3 ).

\section{Results and discussion}

At this stage of the research the different modules to estimate the damage value of the subsidence damage to buildings are defined, all of them being flexible to both the spatial extent and detail of available data. It's nationwide implementation for the Netherlands is ongoing and in this paper illustrated considering two subsidence-related damage mechanisms: timber pile degradation and differential settlement of buildings on shallow foundations.

This study showed that the approach relies on the quality of the data and the most appropriate datasets available were discussed through expert elicitation processes. The expert sessions proved it was possible to incorporate experiences from different backgrounds that are interrelated in causing the damages, but that are typically related to separated knowledge and practice areas.

The uncertainty associated with different contributing factors is discussed and point for needs in future developments characterizing the subsidence hazard but also the exposure and vulnerability of the buildings.

Data availability. This paper discusses a methodological approach and underlying research data can be accessed in the sources cited throughout the paper. 
Author contributions. ALC and SK designed the methodological approach, workshops and reviewed available data in close collaboration with MK. ALC prepared the manuscript with contributions from all co-authors.

Competing interests. The authors declare that they have no conflict of interest.

Special issue statement. This article is part of the special issue "TISOLS: the Tenth International Symposium On Land Subsidence - living with subsidence". It is a result of the Tenth International Symposium on Land Subsidence, Delft, the Netherlands, 17-21 May 2021.

Acknowledgements. This research has been supported by Deltares (Strategic Research Fund). The application of the methodology for the Netherlands was supported by Dutch knowledge program NKWK - KBS that promotes climate resilience cities. The authors would like to thank Stichting CAS and KCAF and attendees to the expert workshops for their contributions.

Financial support. This research has been supported by Deltares (Strategic Research project 11203775).

\section{References}

Burland, J. B. and Wroth, C. P.: Settlement of Buildings and Associated Damage, Settlement of Structures, conference organised by the British Geotechnical Society, April 1974, Cambridge, UK, 611-764, 1974.

F3O: Guideline for Investigation and Assessment of Wooden Pile Foundations under Buildings, Gouda, the Netherlands, 2014.

Hoogvliet, M., Buma, J., and Oostrom, N.: Schades Door Watertekorten En - Overschotten in Stedelijk Gebied, Deltares Report 1205463-000, Delft, the Netherlands, available at: http://publications.deltares.nl/1205463_000a.pdf (last access: 26 February 2020), 2012.
KCAF: Wat Doe Ik Als Bestuurder Met (Mogelijke) Funderingsproblemen?, 1-16, available at: https://www.kcaf.nl/ (last access: 26 February 2020), 2012.

Klaassen, R. K. W. M.: Life Expectation of Wooden Foundations - a Non-Destructive Approach, in: International Symposium on Non-Destructive Testing in Civil Engineering (NDT-CE), 1517 September 2015, Berlin, Germany, 775-779, 2015.

Lixin, Y., Jie, W., Chuanqing, S., Guo, J. W., Yanxiang, J., and Liu, B.: Land Subsidence Disaster Survey and Its Economic Loss Assessment in Tianjin, China, Nat. Hazards Rev., 11, 35-41, 2010.

Salerno, E.: Evaluation of Economic Loss Related to SettlementInduced Damage to Buildings Resting on Piled-Foundations?: Case Studies in The Nethelands, Università Degli Studi Di Salerno, Salerno, Italy, 2017.

Schreurs, E. C. W.: Deterioration of Timber Pile Foundations in Rotterdam, Faculty of Civil Engineering and Geosciences, TU Delft, Delft, the Netherlands, 2017.

UNISDR: A/71/644, Report of the Open-Ended Intergovernmental Expert Working Group on Indicators and Terminology Relating to Disaster Risk Reduction, available at: https://www. preventionweb.net/files/50683_oiewgreportenglish.pdf (last access: 26 February 2020), 2016.

van den Born, G., Kragt, F., Henkens, D., Rijken, B., van Bemmel, B., and van der Sluis, S.: Dalende Bodems, Stijgende Kosten, Den Haag, the Netherlands, Uitgeverij PBL, report number 1064, available at: https://www.pbl.nl/sites/default/files/downloads/ pbl-2016-dalende-bodems-stijgende-kosten-1064.pdf (last access: 26 February 2020), 2016.

Warren, J. P. and Jones, L. L.: Land Subsidence and Associated Externalities in the Coastal Area of Texas, Journal of Agricultural and Applied Economics, 7, 111-115, available at: https://econpapers.repec.org/RePEc:cup:jagaec:v:7:y:1975:i: 01:p:111-115_01 (last access: 26 February 2020), 1975. 